\title{
Exploration of Ethics as Moral Substance in the Context of Corporate Governance
}

\author{
Zaleha Othman \\ College of Business, University Utara Malaysia \\ Sintok, 06010, Kedah, Malaysia \\ E-mail: zaleha@uum.edu.my \\ Rashidah Abdul Rahman \\ Accounting Research Institute, University Technology MARA \\ Shah Alam, Selangor, Malaysia \\ E-mail: shida@salam.uitm.edu.my
}

Received: February 17, $2011 \quad$ Accepted: March 30, $2011 \quad$ doi:10.5539/ass.v7n8p173

\begin{abstract}
The Corporate Governance guidelines, rules and regulations were introduced to guide corporations towards good governance practices. However, there seem to be contradicting events that projected otherwise. The series of corporate scandals seems to be giving the impression that there is something lacking in the present corporation governance practices among the corporations, in particular, the public listed companies. Several opinions were gathered in answering this lacuna and the outcome seems to pin point to the lack of moral element in the present corporate governance practices. Thus, this study attempts to explore ethics aspects as a moral substance in relation to corporate governance. Guided by the subjectivity of the research issue, the qualitative approach was used to investigate the subject matter. Specifically, purposive sampling was used. The study found various ways to embed ethics in promoting morality in corporate governance practices among the corporations in the study. The ethical content developed in the corporations guide the corporate business practices, and, hence, motivates good governance, i.e. accountability, responsiveness, responsibility and transparency. Ethical principle, ethical position and ethical structures are the three main elements of ethics that emerged from the analysis of the research data that drive the corporations towards inclusive governance practices. In addition, process of integrating morality in governance is also part of the initiatives able to guide towards good governance. Overall, the study described a new scope of corporate governance framework. The various emergent patterns answered the question ethics is the moral substance that can be incorporated into corporate governance practices. Generalization of the findings would be difficult due to the limitations of the scope, hence an in-depth case study is proposed for future research to generate deeper and rich description of the issue.
\end{abstract}

Keywords: Corporate governance, Moral, Ethics, Qualitative, Interpretive, Ethics content

\section{Introduction}

The desire to achieve high standards of corporate governance practices is clearly emphasized by the Malaysian High Level Finance Committee in the Report on Corporate Governance, February 1999, which states: "The statement of best practices is designed to guide companies into achieving the necessary high standards of corporate behavior" (para 2.5, p.11). However, in the last two decades standards of corporate behaviour received criticism. There are debates on the standard of corporate governance among corporations worldwide. The main issue is the inadequacy of the present structure of corporate governance (Arjoon, 2005). The inadequacy of the corporate governance structure is often related to the lack of focus on moral obligation. The focus of corporate governance structure as stated is designed to fit economic logic, thus, the focus has always been on structure rather than the morals of the practice. Several corporate governance scholars (Letza, 2007) have indicated that there is a need to understand corporate governance from a moral perspective. Thus, this study attempts to explore ethics as a moral substance, in the context of corporate governance practices. 
The paper is organized as follows: the next section discusses the relevant literature on issues pertaining to ethics and its importance in the corporate governance domain, followed by the description of the research method. A discussion on how ethics guide corporate governance practices is presented after the methodology section. The paper ends with the conclusion and the limitations of the research as well as suggestions for future research.

\section{Prior literature}

Corporate governance is commonly defined as 'a system that directs and controls the organization'. Deliberation concerning the direction and control is often linked with the corporate governance practices of an organization towards wealth maximization. Recent debates on corporate governance argue that the present corporate governance concepts are incorrectly described and do not fit all corporations (Sternberg, 1997), that they are superficial, neglect to consider the human side of governance (Sonnenfeld, 2004) and lack moral obligation (Arjoon, 2005). The focus on economic logic is what leads corporate governance towards wealth maximization, thus, neglecting to consider non-economic logic, and, in particular, moral obligations.

In relation to the above, empirical evidence has been reviewed to support ethics as a solution to improve the corporate governance concept. However, in reviewing the literature, there is a dearth of research that encapsulates the ethical contribution in the domain of corporate governance. Although there are studies (i.e. Felo, 2001; Long \& Driscoll, 2007; Mele, Deberljuh \& Arruda, 2006) concerning ethics as a mechanism that influences corporate governance, the depth of the issue is still in its infancy.

The focus on ethics in governance usually concentrates on ethical structure as a mechanism to improve governance. For example, $\mathrm{Wu}$ (2006) examined ethical structure and its influence on corporate governance practices. A survey was conducted among 500 listed and OTC companies in Taiwan to investigate the link between the ethical structure and corporate governance practices. The study found that the ethical structure (i.e. supervision and balancing) is positively related to corporate governance practices. Wu's (2006) study highlights the importance of ethical structure in establishing corporate governance practices. However, it is observed that the study of $\mathrm{Wu}$ (2006) was limited to an examination of ethical structure. $\mathrm{Wu}$ (2006) neglected to include the wider perspective of ethics. Similar issues are noted in several other studies (i.e. Felo, 2001 and Mele, Debeljuh \& Arruda, 2006). Generally, studies limit their investigation to ethical programmes. Empirical evidence indicates that there is an increase of ethical programmes in relation to corporate governance. For instance, Mele et al. (2006) examined the implementation of ethical programmes and corporate governance practices among 500 companies from three countries (Spain, Argentina and Brazil). The survey results indicate that companies that incorporate ethics have multiple formal ethics documents. The study also found that the common formal ethics documents that the companies focus on are code of ethics, corporate mission and corporate value statements. Code of ethics, for example, is the most popular ethics document noted that influences the governance practices among the survey companies. The study of Mele et al. (2006) suggests that implementation of an ethics programme is an important mechanism to build commitment to inclusive practices. However, there is empirical evidence that indicates otherwise. Felo (2001), for instance, examined the relationship between the ethics programme and corporate governance conflict of interest among 137 American companies listed in the Association of Investment Management Research (AIMR). Surprisingly the study found no difference in relations to ethics programmes and how companies deal with corporate governance conflict between companies with an ethics programme and those without. However, the study indicates that the involvement of outside board of directors influences activities related to ethics in comparison with companies that have fewer outside board of directors. Felo's (2001) study suggests that outside board of directors establish ethical awareness in building governance practices. Such a suggestion is also found in other studies. Various empirical evidence that has been cited (i.e. Kimber \& Lipton, 2005; Rossouw, 2009), found such contention, i.e. that the board of directors ethics influence governance. For example, Rossouw (2009) examined ethics content and governance models and found that the behaviour of the board of directors influences the presentation of the governance model. Kimber and Lipton (2005) indicate that the ethical orientation and integrity of the board and executive influenced the development of the corporate governance model in four countries in Asia (Australia, China, Singapore and India). Analysing the four countries governance models in terms of ethical content, the study found that there is a diversity of ethical content noted among the four sampled corporate governance models. Generally, the findings indicate that the higher the awareness of ethics among the board and stakeholders, the more ethical content is noted in the governance model, indicating that there is an association between ethics orientation and development of the governance model.

The above empirical evidence highlights that ethics support governance practices. However, the issue of ethics in governance has yet to be deeply researched. As noted above, much of the evidence surrounds the structure as a device to enhance governance practices. An exploration of the ethical perspective is required to develop a deeper 
understanding of how ethics can lead inclusive governance practices. The present study attempts to fill the gap by examining the process of ethics as a guide towards inclusive governance.

\section{Research Method}

Corporate governance concepts are often referred to in the literature as being complex and subjective. As the nature of the governance issue is subjective, social constructionist ontology is adopted. Easterby-Smith, Thorpe and Lowe, (2002) suggest that a study that is subjective and requires interaction with people should apply social constructionist ontology. Social constructionist ontology observes reality through social interaction with, rather than focusing on the fundamental laws (as viewed by the realist ontology). Making sense of the reality through the different views shared by people illustrates the social process. In relation to the present study, making sense of the issue through the lens of the people represents the issue of corporate practices related to the moral (i.e. ethics) issue. In doing so, a qualitative approach is appropriate. Learning the meaning from the perspective of the respondents establishes the nature of the research that requires qualitative approach. The qualitative approach requires a rich description of data. In order to obtain the rich description of the data, the enquiry technique is pursued. The enquiry technique involves the process of sample selection, selecting the method of interview, and analysing text corpus. In addition, to confirm the validity of the data, the study used multiple sources (i.e. documents and interviews) as the data collection method, hence, supporting the rigour in the methodology process of evidence gathering.

\section{Sample selection}

The present study uses purposive sampling for sample selection. Silverman (2005) stated that purposive sampling is sample selected based on appropriateness of the case based on the feature or process of interest of the research. The sample involved corporations as the sample of the study. The corporations are selected based on the quality of their practices and high standard of governance. The corporations are ranked among the corporations listed in the Corporate Governance Survey Report 2008 conducted jointly by the Minority Shareholders Watchdog group and Nottingham University, Malaysia. Fifteen companies from the list were selected. Selection was based on several factors such as accessibility of the respondents, and suitability of the corporations as a sample.

\section{Selection of method of enquiry}

The qualitative technique was employed (i.e. interview, observation and document analysis) to explore the issue of the study. The qualitative technique such as mentioned above provide rich description of the research issue. Face to face interview enable to provide insightful narration of the issue. Document analysis, on the other hand, triangulate the data gathered from the interview and observation support the validity of the data gathered from interview. Normally, the length of interviews was approximately 90 minutes. Most of the interviews were conducted at the premises of the participants. In order to gain insights into the issue, open ended interview questions were used. Open ended interviews give freedom to the respondents to speak their mind freely. In respect of the issue of the study, such an approach is important to seek and understand the ethical process in the context of corporate governance. A conversation-discussion based approach was adopted for the interviews. The idea of having such an approach is due to the sensitivity of the topic, thus, a more interactive situation is preferred.

\section{Data analysis}

The study employs the suggestion of Miles and Huberman (1994) concerning data analysis techniques where the evidence gathered was categorized into themes. Miles and Huberman (1994) suggested three processes for analysing qualitative data - data reduction, data display and conclusion drawing. The data reduction phase involved two main processes - transcription and coding of data. Qualitative software, i.e. NVIVO was used to assist the researcher in transcribing and coding the data, which is also known as the data management process. However, interpretation of the data was conducted manually.

\section{Findings}

This section describes the analysis of the evidence gathered from the interviews, document analysis and observation. It answers the aim of the study, i.e. explores ethics as the substance of inclusive corporate governance. Based on the analysis of the research data, several themes emerged. Diagram 1 offers a conceptual model of inclusive governance based on the categories of the themes that emerged from the data. The diagram depicts the conceptual description of the findings of the ethical dimension that is found to influence inclusive governance practices among the study sample.

\section{Insert Diagram 1 Here}


Diagram 1 describes the ethical content that emerged from analysis of the data from the fifteen Malaysian sampled companies selected for the study. Three categories of ethical content discovered from the data. The core components of ethics are; ethical principle, ethical position, and ethical structures. Each core component identifies several ethical elements that are embedded in the corporations. Each component was described as contributing towards inclusive governance practices among the corporations in the study. The following section explains the process of integration for each of the ethical elements as a subject that influences the governance practices among the sample study.

\section{Ethics content as the moral substance of corporate governance practices}

There are various ways to embed ethics in promoting morality in corporate governance practices among the corporations in the study. The respondents stated that the ethical content developed in their corporations guides the corporate business practices, and, hence, motivates good governance, i.e. accountability, responsiveness, responsibility and transparency. Ethical principle, ethical position and ethical structures are the three main elements of ethics that emerged from the analysis of the research data that drive the corporations towards inclusive governance practices. Below is an explanation of the various ethical contents translated by the corporate reality that improves their governance practices.

\section{Ethical principle}

The findings of this study indicate that ethical principle is the belief manifested by the corporation. The data revealed that ethical principle comes in the form of corporate philosophy. Corporate philosophy brings forth the meaning of the corporation beliefs that are commonly translated into the culture adopted in the corporations. Mission and vision is part of the corporate manifesto termed as the corporate philosophy. The findings of the study suggest that mission and vision of corporations stimulate inclusive governance practices. The respondents revealed that corporate members are constantly reminded of their respective corporations mission. For example, the respondents revealed that the corporate mission is often documented and clearly displayed at the premises of the corporations such as at the entrance of the premises It was also revealedthat the majority of the corporations that addressed integrity as their corporate mission, communicate their philosophy through documentation. Company no. 2 for instance, linked their business activities with integrity for all levels of management. The chairman, for example, constantly, highlighted integrity as the foundation of their business activities. Due to its nature of business (i.e. financial services), the company implanted integrity into the business activities. For companies involved in financial services, corporate reputation is crucial to sustain their business. Previous study also supports the contention that mission and vision contribute towards corporate practice (Svenson \&Wood, 2004).

Ancillary findings related to corporate philosophy were also shared by several respondents. For example, as mentioned by the respondent from company no.1, corporate philosophy should not be influenced by factors that could destroy the corporation. The respondents referred to political agenda as factors that could destroy corporation reputation. As claimed by respondents, political agenda should not interfere with the mission and vision of corporations. Respondent no. 1, voiced his concern regarding the corporate philosophy of the government linked companies. He believes that many of the corporate decisions are influenced by third parties. In his opinion, the issue of corporations having to deal with interference from third parties raises the concern for conflicting governance interest. This, based on his informed view, could divert the mission and vision of the corporations, and impact the corporate accountability towards the stakeholder and society.

The findings revealed an interesting result related to the ethical principle. The respondents highlight that corporate ethical principle requires a navigator. The navigator is positioned in the corporations to guide ethical behaviour among corporate citizens and external parties related to the corporations. The respondents highlight that commonly there are certain individuals that hold positions in the corporation that are able to assist the corporation to realize the corporate philosophy. General findings indicate: 1) top management such as chairman, board of directors, 2) middle management such as company secretary, and 3) external actors such as independent body, are actors that are able to establish the corporate philosophy. The research termed the above position as ethical position. Deliberation of the ethical position is explained in the next section.

\section{Ethical position}

Ethical position, as socially constructed, is a job description or position that assists corporations to establish ethical initiatives to enhance their governance practices. Argandona (2007), in his explanation of Professor Perez Lopez, expressed that Perez Lopez emphasized that an organisation is represented by people who are relevant in decision making. Ethics represents the moral virtues of the people that guide decision making. As such the ethical position is important to build moral virtue among members of the organisation. The theory of decision of 
Perez supports the findings of this research that the people are important drivers of ethical decision making. As pointed out by Argandona (2007), ethics in relation to the decision theory of Perez echoes that ethics balances the people and the organisation. Ethics, as interpreted by Perez, is the evaluation of the reality regardless of the economic gain or effectiveness, as his organisation theory (i.e. focus on organisation as the premise to provide services, facilitate work and develop people's ability to serve and be useful to others) emphasized that an organisation's survival depends on the ethical quality of the people.

Close analysis of the research data indicate that the ethical position comes in the form of internal and external influences. The internal position is dominated by management of the corporations, commonly, among the company secretary, human resource officers, and internal auditors. These groups are termed as ethics officers. Although each position is confined to a specific job specification, the common nature of job function identified by the respondents indicates these job designations as ethics officers. Other ethics positions suggested by the respondents are directorship, establishment of independent body and whistle blowing custodian.

\section{Ethics officer}

Creating a description of an ethics officer is a form of ethical initiative that is perceived as a premise for corporations to promote inclusive governance practices. Respondents no. 4 and no.10 suggest the establishment of an ethics officer to promote commitment of ethical behaviour in achieving a high corporate governance standard. However, scepticism has been voiced relating to the position of the ethics officer. For example, the respondent from company no. 3 is doubtful of the implementation of an ethics officer:

- ' $\quad$... I think it is a bit too soon to have someone in that position in Malaysia at this point in time...'

He explained why:

- $\quad$ '... you see in Malaysia we are used to the way we do things here. Any new change is a big thing unless we enforce it. That is a governance issue...'

Empirical evidence concerning ethics officers revealed that they are the custodians that guide corporate members to deal with ethical matters. The ethics officer acts as a mediator between the employees, stakeholders, and management and also the board. Llopis, Gonzales and Gasco (2007), confirmed the finding that the ethics officers has an important job description in an organization.

\section{Directorship as profession}

Another ethical position explained by the respondents that assists corporations to nurture ethics is the directorship position. Making the director position professional is the exact impression given by the respondents. As stated by one respondent, 'make directorship as a profession' (no.13). He expressed that independent directors should be made into a profession in order to hold the director to be more accountable and responsible. One particular respondent confirmed the link between directorship and inclusive governance practices. He strongly believes that directors, as pillars of governance, should be equipped with knowledge and skill. He believes there is lack of professionalism for directorship in Malaysia. In making sense of the reality, the respondent perceived that it is not easy as there are factors that could affect the effectiveness of the profession. Such is his thought - 'certainly any board will take people that they can work with and how do you define working with - 'yes' man?

Concerning the process of directorship, he suggests a job portal for directorship. Hence, a database of directors could be created. As such, suitable applicants can apply and suitably qualified directors can be included in the database. Integrity value, qualification, experience, and psychometric tests are some of the essential requirements proposed. Based on the requirements, ratings for directors can be created. Thus, these ratings are useful for corporations to select their future directors. 'So if you want directors with ethical value certainly their past record is the evidence', conveyed respondent no.13. This is a way to sideline directors who are involved or have a record related to unethical conduct.

\section{Independent body}

Conformance does not necessarily mean performance, is the perception of the respondents. One particular respondent, who is professional and has vast business experience, suggests that the establishment of an independent body is an inclusive check and balance structure. This is what he says:

- $\quad$ '... I did suggest that an independent body should be the body that will do on a general basis an assessment on corporate governance practices. Give them ratings, as it is done in companies. At least the user and interest investor will know at a glance the corporate governance practices. Oh... company needs to comply 
more, needs to give reassurance... and tell the public the level of corporate governance practices in terms of conflict and the level of conflicts and perspective' (respondent no.12).

Concerning the rating, this particular respondent announced that the methodology of rating must be structured effectively. He commented that if it is not designed properly and accurately it would impact on the reliability of the rating. He voiced that ethics should be one of the elements in the rating format. How do the boards fuse ethical standards in their day-to-day operation in the company as well as the board? This needs to be addressed. This respondent suggests that the Malaysian Institute of Corporate Governance (MICG), being an independent body, should take the responsibility as an independent body in guiding Malaysian companies towards ethical governance. As emphasised by respondent no.12:

- $\quad$ ' $\ldots$ the aim of the minority shareholder although long term, is important, he wants a constant flow of dividend. That is why they query the directors, why they want to invest in certain risky projects, especially when the majority shareholders are in a position to influence the decision. That is why we need an independent view given by independent directors and perhaps on behalf of the minority shareholders why such investment could be inclusive or otherwise'.

\section{Whistle blowing custodian}

Whistle blowing is a position recommended by all of the respondents. They perceived that it is very important for corporations in this era to initiate a whistle blowing position. A whistle blowing position, such as a legal officer, should be appointed to guide activities, such as building whistle blowing intranet facilities, imposing whistle blowing act, and appointing officers to serve the purpose. As stated by respondent no.3

- $\quad$ '... Whistle blowing is something we are trying to initiate, enhance in this country. The general perception of whistle blowing is if I tell upon you I will get the sack so people fear for their job.... we would not want that to happen because the value of the company might just go down. Shareholders will loose...there must be some system within the company that allows whistle blowing to be done without reprimanding the person or repercussions that affect their job'.

It is important for the corporation to initiate a venue for the above to materialize. The Company Secretary (CS) and Internal Auditor (IA) are suggested as suitable for the responsibility towards enabling the above objective. Simply put by a respondent:

- $\quad$ '... there must be one person they can complain to... somebody appointed to be responsible, to be the person that they can channel through and be assured that they are protected'.

\section{Ethical structure}

The findings of the study indicate several ethical structures that the respondents perceive as being associated with enhancing inclusive governance practices. Codes of ethical conduct, key performance indicators and ethical reporting are the structures explored. This research finding, that ethical structure drives governance practices, is supported by previous studies (i.e. Downes and Russ, 2005). Downes and Russ (2005) termed ethical structure as tangible ethics content.

\section{Codes of ethical conduct}

Ethics cannot be codified, the foundation of ethics such as honesty, integrity, responsibility, and trust is inbuilt. This perception is made by the majority of the respondents who believe that ethics is built in a person from a young age (respondent no.1, 2, 6, 7, 8, and 9). Although such contention is voiced by several of the respondents, others nonetheless, agree that an explicit ethical structure can be formalized. They believe the ethical artefacts assist in resolving ethical dilemma. An inclusive example of ethical structures that has been practiced widely is the code of ethics. Below, several of the respondents' points relate to ethical structure building inclusive governance practices. Comments made by respondents regarding making ethics formal include:

- ' '... [code of ethics] is the pillar of success for multi-national corporations. It is a long term investment. You have to believe in it, have to treat it as a culture and it has to start from the chairman of the company right down to the country head'.

- '... If we are going to have a public limited company, which is trusted by the investors we must have a certain code of ethics'.

- '... we provide this [show the code of ethics guideline] to our suppliers so we can say if you want to do business with us you must show us you are like this. Our investors as well, they have their own sort of supplier code of business ethics, code of conduct and so on' (respondent no 11). He pointed out that the present culture in the corporation has changed and that this is transferred to the parties doing business with the corporation. The 
present corporation mission and vision is towards building the nation, thus, re-structuring of the corporations is working towards that. What the corporation now believes in is professionalism'.

How can a code of ethics advocate elements of corporate governance such as transparency or fairness? A code of ethics can address the risk involved if directors were to break the code. A code of ethics is an ethical policy that reflects the right and wrong that directors can refer to in the absence of a legal understanding. Belief in the code of ethics, however, is integral. The comment made by respondent no 2 indicates that the code is a formal way of creating a culture of 'doing the right thing' in a corporation. Respondent no. 2, who has experience working in Multi National Corporations, has high regard for the code of ethics and deems it central in his work routine. His experience working in a pharmaceutical company taught him not to ignore ethics in dealing with business activities. He states that MNCs are highly conscious of ethics and regard ethics as an important culture in doing business.

Endorsement of the code of ethics is another point perceived as an important part of ethical governance. The respondents believe that signing of the code is not a cosmetic process but reinforces the significance of the code. Endorsing the code is a process of taking ownership of the responsibility and accountability. It is the process, which involves all levels of management. Thus, the code must be made known to all respective parties involved -employee, supplier, customer, and board. This is the voice of many respondents who said that one must believe in the code in order to make it a way of life. Making the code work means making the code part of corporate inclusive practices interpreted from the socially constructed belief of the respondents. A number of respondents (respondents no.2, 10) highlight their belief that the code is more than just a formal document. It is a contract that advocates what is written. For example respondent no. 2 states:

- $\quad$ '... I was held responsible to sign promotional material as the last signature. If any thing goes wrong I am responsible'.

The above statement is an example of keeping directors responsible and accountable in their governance practices. Vigilance and carefulness are the elements of inclusive ethics described by the respondent that could lead directors to be more accountable and responsible.

Congruent with the literature, a code of ethics is empirically proven to influence good governance. For example, Payne and Landry (2005) found that a code of ethics influences good governance practices. Payne and Landry's (2005) study revealed seven core values (consistency, respect individual, autonomy, integrity, justice, utility, and competence) as concepts that serve as professional attributes towards good business practices. Code of ethics, as perceived by Schwartz, Dunfee, and Kline (2005), includes values such as honesty, loyalty, integrity, responsibility, citizenship and fairness. A similar deliberation of codes of ethics in the present study reveals that codes of ethics guide honesty, integrity and responsibility.

\section{Key performance indicators as the format of evaluation}

Responsibilities of directors are subjective, and, thus, difficult to measure. For example, director's remuneration, which is based on performance, is a subjective issue. Performance, which is often related to directors' involvement in decision making, is a subjective measure as directors work collectively. Exploring this issue, respondent no.12 believes that some kind of key performance indicator should be created to index the executive or non executive evaluation of performance. The KPI of board remuneration is the main evaluation basis suggested by the majority of the respondents.

- ' $\quad$... that remuneration is commensurate with the position because things like responsibility are very difficult to measure. So it's subjective, that means they should come out with some kind of basis to evaluate this'. How can this be done? The respondent explains that “. .. based on certain markers, certain benchmarks. He said, '... I benchmark you on your performance based on certain criteria'.

- $\quad$ '... The conduct of our affairs, the objective, transparent and accountability - we try to cascade it down to our people as well then they conduct their affairs objectively, independently. We try to make it a KPI for our balanced scorecard to make this as one of the criteria'.

\section{Reporting}

Reporting, as described by the participants, stimulates inclusive governance practices. There are two main means of ethical reporting described by the respondents, namely, audit report and quarterly reporting.

Audit report is a formal evidence of corporate ethical conduct. As mentioned by respondent no.1: 
- ‘... in your audit report, you say, we have an auditor. The accounts of the company are prepared in accordance with the approved auditing standards in Malaysia. So the approved auditing standards in Malaysia include complying with ethical standards, quality control, and auditing standards'.

Another form of ethical means that translates into inclusive governance practices, as voiced by respondent (no.6), is through quarterly reporting. This is a monitoring assessment that can keep the agent of governance systems vigilant of their conformance and performance. The social view of respondent no. 6 is that quarterly reporting is substantial but not the only means of check and balance strategy in promoting ethical governance.

\section{Process}

The ethics process is defined as the proper procedure and process of administrative activities and practices in companies. The majority of the participants consider a formalized communication process as one form of administrative process that is ethics.

The respondents believe in communicating ethical values to all levels of management. Ethical programmes should be set up in order to communicate desirable governance practices. How is this done? One particular respondent shared his experience; every new recruit to the company spends their first week in an orientation programme where the code of business practice is explained. The objective of the programme is to ensure that new recruits understand the practices of business conduct in the company and respect the expectation of the company towards ethical behaviour. In order to bind their responsibility, accountability and duties, the recruits have to sign a code of business practice in their first week of employment.

Another form of communicating ethics shared by the respondents is by disclosing information related to unethical cases to the staff. The respondent states that disclosing through a newsletter a number of cases and the penalties involved is an inclusive way of increasing awareness, while simultaneously instilling caution in the staff.

Relaying information that the company does not tolerate unethical behaviour is another ethical move that the respondents identified. As shared by respondent no.11, such a message is spread to all stakeholders of the company. The manifesto of the company to operate business fairly, ethically and in full compliance with all laws and regulations is clearly conveyed to everyone involved directly or indirectly. For example, a detailed Code of Business Practices is designed as a guideline for all the relevant internal and external parties involved with the company's activities. This Code of Business stipulates how each relevant individual should react and behave in line with the expectation of the company's inclusive governance practices. Specifically, the respondents company formulated a vendor's code of business practices. The vendor codes consist of practices that are expected from vendors and the guidelines that are formulated by the company in order to maintain a certain standard of integrity from both parties (the company and the vendor). "All companies doing business must also sign a code of business practice, through which we communicate our principal of doing business, confirming that they have read and understood the code. Vendors, who are found to be working against these ethical practices, would no longer be allowed to do business with us". According to him, it is the entry point for external perception to do business with the company.

Concerning the implementation and effectiveness of the code, the company has a specially established office of Business Practices to provide policy guidance and facilitate compliance with the code. Continuous efforts are taken by the office of Business Practice to look into ways to encourage a high standard of business conduct and ethics in the company; benchmarks for best practices are observed to further improve the company's business practices.

Formal communication, as described above, is indeed an attempt to enhance governance standards, however, adverse perceptions were also identified. A few respondents $(1,7,8)$ are not so keen on institutionalized ethics. They view institutionalized ethics as meaning just 'bringing out the law and legalising the structure'. They tie the success of the institutionalization of ethics with people. People as the guidance of the structure need to be nurtured to act ethically. Respondent no 7, for example, shared his experience of dealing with professionals breaching the law, although he said the professionals are bound by a code of professional ethics. In addition, respondent no.1 sees institutionalized ethics as just another creation of a standard. He also stresses human governance rather than the structure of the governance practices. He pointed out that codes or standards would not guarantee inclusive behaviour.

\section{Conclusion}

This study described a new scope of corporate governance framework. This study did not set out to test any assumption, but to explore and explain the views from society and to identify the meaning underlying their 
perceptions. Designed with an interpretive epistemology approach and based on the social construction nature of reality, several emergent patterns were discovered. The various emergent patterns answered the question of which components of ethics can be incorporated into corporate governance practices. Interpretation of the categories indicates several key ethics contents: ethics principles, ethics position and ethic structure These ethical components are perceived as elements that would guide ethical governance practices. Integration of these variables would make a difference to transparency, accountability, and responsibility etc., hence, contributing towards a new paradigm of governance. In conclusion, it is indeed necessary to embed an ethical structure in the corporation.

The present study has scoped its exploration of the issue focusing on the enquiry method. Generalization of the findings would be difficult due to the limitations of the scope. Nonetheless, the richness in the description of data would counter the limitation. The conceptual framework illustrates categories of ethical elements that are important for deliberating inclusive governance practices in organizations.

In order to enhance the finding, an in-depth case study is proposed for future research.

\section{References}

Argandona, A. (2008). Integrating Ethics into Action Theory and Organizational Theory. Journal of Business Ethics, 78, 435-446. doi:10.1007/s10551-006-9340-x, http://dx.doi.org/10.1007/s10551-006-9340-x

Arjoon, S. (2005). Corporate governance: An ethical perspective. Journal of Business Ethics, 61, 343-352.

Downes, M., \& Rush, G. (2005). Antecedents and consequences of failed governance the Enron example. Corporate Governance, 5(5), 84-98.

Easterby - Smith, M., Thorpe, R., \& Lowe, A. (2002). Management research an introduction. New York: Oxford University Press.

Felo, A. (2001). Ethics program, board involvement and potential conflicts of interest in corporate governance. Journal of Business Ethics, 32 (2), 205-218.

Joint study by MSWG \& The university of Nottingham. (2008). Corporate governance Survey Report 2008. Kuala Lumpur: MSWG.

Kimber, D., \& Lipton, P. (2005). Corporate governance and business ethics in the Asia - Pacific Region. Business and Society, 44(2), 178-210. doi:10.1177/0007650305275300, http://dx.doi.org/10.1177/0007650305275300

Llopis, J., Gonzales, R.M., \& Gasco, Fl.J. (2007). Corporate governance and organizational culture: The role of ethics officers. International Journal of Disclosure and Governance, 4(2), 96-105.

Long, S.B. \& Driscoll, C. (2007). Codes of Ethics and the Pursuit of Organizational Legitimacy: Theoretical of Empirical Contributions. Journal of Business Ethics, 77, 173- 189. doi:10.1007/s10551-006-9307-y, http://dx.doi.org/10.1007/s10551-006-9307-y

Mele, D., Debeljuh, P. \& Arruda, C.M. (2006). Corporate ethical policies in large corporations in Argentina, Brazil, and Spain. Journal of Business Ethics, 63, 21-38. doi:10.1007/s/10551-005-7100-y, http://dx.doi.org/10.1007/s/10551-005-7100-y

Miles, M.B., \& Huberman, A.M. (1994). Qualitative data analysis: an expanded sourcebook. London: Sage Publication. Newbury Park, CA: Sage.

Payne, D., \& Landry., B. (2005). Similarities in Business and IT Professional Ethics: the need for and development of a comprehensive code of ethics. Journal of Business Ethics, 62. doi:10.1007/s10551-995-3439-3, http://dx.doi.org/10.1007/s10551-995-3439-3

Rossouw, J.G. (2009). The ethics of corporate governance Crucial distinctions for global comparison. International Journal of Law and Management, 51(1), 5-9.

Schwartz, M., Dunfee, W.T., \& Kline, J.M. (2005). Tone at the Top: An Ethics Code for Directors? Journal of Business Ethics, 58, 79-100. doi:10.1007/s10551-005-1390-y, http://dx.doi.org/10.1007/s10551-005-1390-y

Silverman, D. (2005). Doing qualitative research. Los Angeles: Sage Publications.

Sonnefeld, J. (2004). Inclusive governance and the misleading myths of bad metric. Academy of Management Executive, 18(1), 108-113.

Sternberg, E. (1997). The defects of stakeholder theory. Corporate Governance, 5(1), 3-10. 
Svenson, G., \& Wood, G. (2004). Public sector ethics in Sweden: a 4P model of internal and external determinants in codes of ethics. Corporate Governance, 4(3), 54-64.

Wu, F.C. (2006). The study of the relationship among ethical consideration, family management, and organizational performance in corporate governance. Journal of Business Ethics, 68, 165-179.

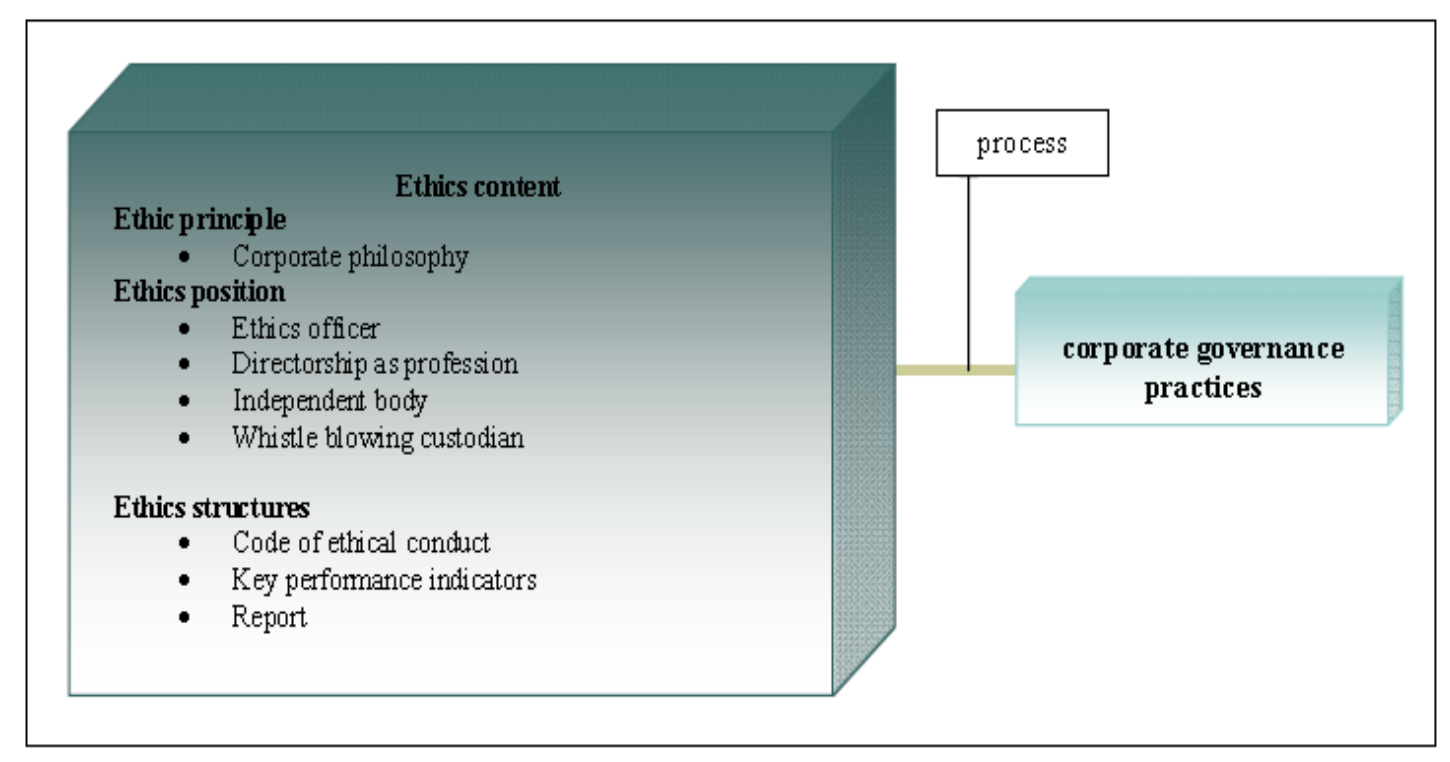

Diagram 1. Conceptual model of ethics content that promotes inclusive governance 